\title{
The Geneva Smoking Pictures: Development and Preliminary Validation
}

\author{
Yasser Khazaal $^{\mathrm{a}} \quad$ Daniele Zullino $^{\mathrm{a}} \quad$ Joël Billieux ${ }^{\mathrm{a}, \mathrm{b}}$ \\ ${ }^{a}$ Department of Mental Health and Psychiatry, Division of Addictology, Geneva University Hospitals, Geneva, \\ Switzerland; b Psychological Sciences Research Institute, Catholic University of Louvain, Louvain-La-Neuve, \\ Belgium
}

\section{Key Words}

Tobacco $\cdot$ Nicotine $\cdot$ Cue $\cdot$ Pictures $\cdot$ International Affective

Picture System · Addiction • Dependence

\begin{abstract}
Cue reactivity is essential to the maintenance of addictive disorders. A useful way to study cue reactivity is by means of normative pictures, but few validated tobacco-related pictures are available. This study describes a database of smoking-related pictures: The Geneva Smoking Pictures (GSP). Sixty smoking-related pictures were presented to 91 participants who assessed them according to the classic emotional pictures validation provided by the International Affective Picture System (NIMH Center for the Study of Emotion and Attention, 2002). The pictures were rated according to three dimensions: (1) valence (from positive to negative), (2) emotional arousal (from high arousing to low arousing), and (3) dominance (from submissive to dominant). Participants were also screened with the Fagerström Test for Nicotine Dependence. Normative ratings for valence, arousal and dominance of the pictures are provided for the whole sample, as well as separately for dependent $(n=46)$ and nondependent smokers $(n=45)$. Arousal and dominance were associated with greater nicotine dependence, but valence ratings were not. The GSP is a normative database providing a large number of stimuli for investigators who are conducting nicotine and tobacco research.

Copyright $\odot 2012$ S. Karger AG, Basel
\end{abstract}

\section{KARGER}

Fax +41613061234 E-Mail karger@karger.ch www.karger.com (c) 2012 S. Karger AG, Basel

$1022-6877 / 12 / 0183-0103 \$ 38.00 / 0$

Accessible online at:

www.karger.com/ear

\section{Introduction}

Cue reactivity is a key phenomenon in addictive behaviors [1], possibly leading to subsequent substance use mediated by craving or by unconscious automatic processes [2]. In accordance with the crucial role of cue reactivity in smoking behaviors, a growing number of studies on nicotine dependence have reported using tobacco-related pictures [3-5]. These stimuli are of critical importance in addiction research for the study of attentional bias [6] and substance-related cue reactivity (e.g. physiological activation) $[1,7,8]$ as well as functional neuroimaging studies $[9,10]$. Unfortunately, in most studies that have used tobacco and substance-related pictures, the pictures were selected from databases that were not previously validated (e.g. Internet stock photography sources). This led the investigator to include some kind of validation procedure [11-15] in studies that did not have as their primary aim the validation of the pictures, reducing the generalization and the diffusion of the data strictly related to the pictures. Thus, numerous studies have investigated cue reactivity in smokers or other substance abusers by using substance-related pictures selected by the investigators [11] and affective pictures unrelated to substance use taken from a normative validated database (e.g. the International Affective Picture System; IAPS).

This phenomenon is not surprising as the IAPS provides only a few pictures related to tobacco (Nos. 2715 and 2749) or other substances (cocaine, No. 9101; heroin, 
No. 9102; alcohol, Nos. 2600 and 2749). As a result of this lack of available stimuli, several attempts have been made during the last decade to develop new substance-related stimuli. The first database specifically devoted to appetitive stimuli (pictures focusing on food, alcohol, tobacco, and other drugs) was the Normative Appetitive Picture System (NAPS) [12]. The aim of the investigators who developed the NAPS, along the same lines as that in the IAPS, was to provide a dataset of normative stimuli for psychoactive substance and food-related research. Despite the clear improvement related to this initiative, the NAPS comprises only a small number of different pictures per substance (e.g. only six photos related to smoking behaviors). As a consequence, investigators who would like to use the NAPS must use supplementary pictures (leading to the problems mentioned earlier concerning the picture selection method) in order to avoid multiple presentation of the stimuli $[13,14]$.

More recently, a set of 35 pictures related to smoking was created [15] and assessed by using the IAPS validation method. Notably, this allows the use of smoking-related stimuli and other pictures (e.g. control pictures) taken from the IAPS database in the same experiment, as both stimuli have been validated with the same procedure.

In this context, the aim of the current study was to develop a new database of 60 smoking-related pictures: the Geneva Smoking Pictures (GSP). See online supplementary material (www.karger.com/doi/10.1159/000335083). We decided to validate the stimuli according to the IAPS validation of emotional pictures, in the same manner as has recently been done for smoking-related pictures [15] or alcohol-related pictures [16], which significantly increases the number of normative smoking-related stimuli available for research. Another advantage of using the IAPS procedure of validation is that the various dimensions measured (valence, arousal, dominance) have been found to be relevant in addictive disorders $[16,17]$.

\section{Methods}

\section{Participants and Procedure}

The study included 91 participants living in Switzerland (37 men, 54 women). The mean age of the sample was 28.91 years $(\mathrm{SD}=9.14)$ and the mean number of years of schooling was 15.68 $(\mathrm{SD}=3.03)$. The mean years of smoking was 10.46 (range $1-43$, $\mathrm{SD}=7.97)$ and the mean number of cigarettes smoked per day was 13.30 (range $1-35, \mathrm{SD}=8.33$ ). Our aim was to include persons presenting various levels of smoking patterns, from light (less than 10 cigarettes per day) to moderate (10-20 cigarettes per day) or heavy smoking (more than 20 cigarettes per day). Participants were nondeprived smokers at the time of the experiment. The time since the last cigarette was smoked was also measured $(34.2 \%$ smoked their last cigarette between 1 and 15 min before the experiment, $21.5 \%$ between 15 and $30 \mathrm{~min}, 11.4 \%$ between $30 \mathrm{~min}$ and $1 \mathrm{~h}, 7.6 \%$ between 1 and $2 \mathrm{~h}, 7.6 \%$ between 2 and $4 \mathrm{~h}$, and $17.7 \%$ more than $4 \mathrm{~h}$ ). The participants were recruited via advertisement (e.g. at the university and hospitals of Geneva) or by announcements made by investigators of the study. All participants gave their informed consent prior to their participation. After completing a general questionnaire about demographic data (age, gender, activity, years of schooling), participants were asked to assess 60 tobacco-related pictures (see the following subsection) and to complete the Fagerström Test for Nicotine Dependence (FTND) [18]. Participants were tested in groups of 3-15 participants. Several participants who were not available at the time of testing were tested individually in a laboratory. Informed consent forms were kept separate from the completed questionnaires to guarantee the anonymity of the participants. No compensation for participation was given. The entire experiment lasted about $1 \mathrm{~h}$.

Tobacco-Related Picture Selection and Evaluation

The GSP comprises 60 tobacco-related pictures selected from an original set of 200 pictures. Selections were made so as to avoid incorporating pictures that were too similar. All pictures were taken by members of the research team. The 60 selected pictures are subdivided into three types: (1) the product itself (e.g. cigarette packs, a burning cigarette), (2) smoking behaviors (e.g. someone smoking, someone rolling a cigarette), and (3) tobacco-related cues (e.g. an ashtray, a lighter). Figure 1 depicts examples of pictures included in the GSP. The appendix includes a complete list of the 60 pictures with their type (product, smoking behaviors or tobacco-related cues).

The normative rating procedure used to validate pictures of the IAPS [19] was followed as closely as possible. Participants had to rate each picture one by one on the dimensions of valence, arousal and dominance by using a pencil-and-paper version of the SelfAssessment Manikin (SAM) rating system [19]. Participants in the group sessions were seated from 2 to $4 \mathrm{~m}$ in front of a screen on which the pictures were projected (2-4 rows of participants). To limit social conformity bias in group sessions, we took care that participants were not seated too near one another to prevent them from seeing their neighbors' responses. The size of the screen was identical for each group session. Participants in the individual sessions were seated in front of a computer in a quiet laboratory. The picture presentation was run with Microsoft PowerPoint. Participants were told that the study aimed to investigate their appraisal of tobacco-related pictures and they were instructed to assess the pictures by using a rating form containing 60 sets of SAM figures. The investigators who conducted the various sessions (both group sessions and individual sessions) were trained to provide similar explanations about the experiment. Each set comprised three scales to measure the three dimensions of interest on a 9-point Likert scale (valence, arousal, and dominance). The order of the three dimensions measured was randomized across trials. Prior to the assessment of the 60 pictures, instructions were given to clarify the meaning of the three dimensions. The valence dimension was said to vary from positive to negative feelings. More precisely, valence occurs on a continuum from feeling happy, pleased or satisfied on one side (a SAM with a smiling figure; score =1) to feeling unhappy, annoyed or unsatisfied on the other side (a SAM with a frowning figure; score $=9$ ). The arousal dimension was said to 

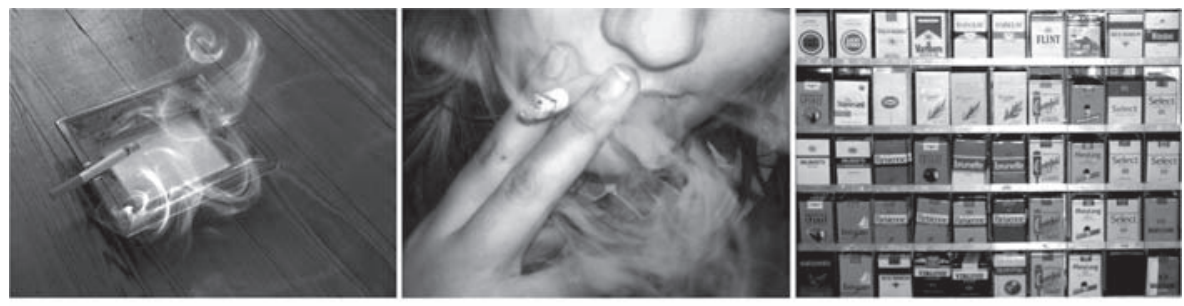

Fig. 1. Sample pictures from the GSP.
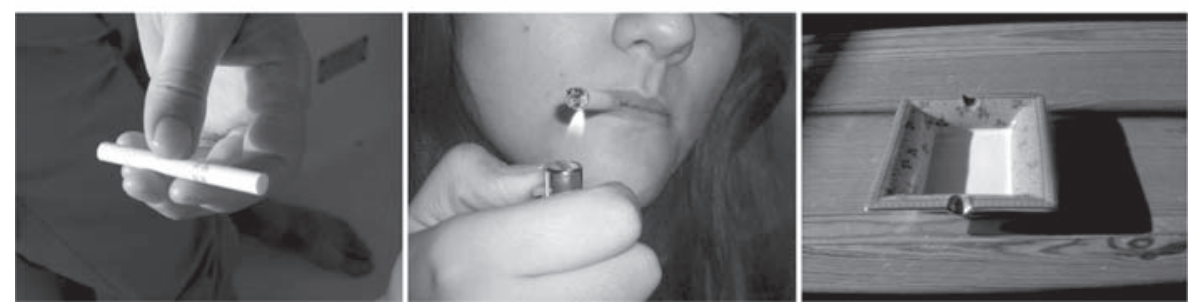

vary from aroused to unaroused. More precisely, arousal occurs on a continuum from feeling stimulated or excited on one side (an excited SAM with open eyes; score $=1$ ) to feeling relaxed or calm on the other side (a sleepy SAM with closed eyes; score $=9$ ). The dominance dimension was said to vary from submissive to dominant. More precisely, dominance occurs on a continuum from feeling influenced and guided on one side (a small SAM figure; score $=1$ ) to feeling influential and in control on the other side (a large SAM figure; score $=9$ ). Participants were asked to rate how they actually felt when seeing each picture (not at the moment that they rated the picture after having just seen it). The rating procedure was as follows: (1) a forewarning slide with the instruction 'Prepare to rate picture X' was presented for $5 \mathrm{~s}$, (2) after this period a picture was presented for $6 \mathrm{~s}$, and (3) after the picture was presented, a 10 -second rating period began with the instruction 'Please rate picture $\mathrm{X}$ on all three dimensions'. Before starting the rating of the 60 pictures, the participants were provided with an example of the sequence, along with commentary by one of the researchers.

\section{Fagerström Test for Nicotine Dependence}

The French version of the FTND [20] measured the level of smoking dependence. The FTND is a self-report instrument with six items rated either from 0 to 1 or from 0 to 3 (depending on the question) that can yield a total score of 10 , with higher scores indicating greater dependence. The FTND has been used in many studies and shown to have positive correlations with several biochemical measures related to the quantity of cigarettes smoked (e.g. saliva cotinine) [18]. The internal consistency and test-retest reliability of the FTND are good [21]. FTND scores of 5 and higher can be interpreted as at least related to moderate tobacco dependence [20]. The reliability coefficient (Cronbach's alpha) calculated on questionnaires with no missing data is excellent $(\alpha=$ 0.78). The mean FTND score in the present sample was 4.22 (range $0-8, \mathrm{SD}=2.92$ ). From the normative data provided by a Swiss sample [20], the FTND scores in the current study characterized 45 participants ( $49.5 \%$ of the sample) as being nondependent smokers and 46 participants (50.5\% of the sample) as being dependent smokers.

Normative Database of Tobacco-Related Pictures

\section{Results}

Descriptive statistics (mean, standard deviations, range) for the three types of ratings (valence, arousal, dominance) are reported in table 1 separately for dependent and nondependent smokers. In addition, the appendix also provides normative data for the 60 pictures of the GSP separately for dependent and nondependent smokers. Correlation analyses were computed between the various ratings of the pictures, revealing valence to be correlated with dominance $(r=0.51, \mathrm{p}<0.001)$ and with arousal $(r=0.53, \mathrm{p}<0.001)$, whereas arousal and dominance were strongly correlated $(r=0.73, \mathrm{p}<0.001)$. No gender effect was observed, whether for valence, $t(89)=$ $0.31, \mathrm{p}=0.75$; arousal, $t(89)=-0.065, \mathrm{p}=0.52$; dominance, $t(89)=-0.13, \mathrm{p}=0.90$; or total FTND scores, $t(89)=1.01, \mathrm{p}=0.31$. Accordingly, separate ratings for males and females are not reported.

Correlation analyses were also computed between actual smoking (years of smoking, number of cigarettes smoked per day, time since last cigarette was smoked) and the subjective ratings of the pictures. The number of cigarettes smoked per day negatively correlated with both valence $(r=-0.27, \mathrm{p}<0.05)$ and arousal ratings $(r=-0.24$, $\mathrm{p}<0.05)$, implying that the greatest number of cigarettes smoked per day is associated with higher pleasure and arousal when seeing the pictures. Years of smoking and time since the last cigarette did not significantly correlate with any of the subjective ratings.

We then computed a 2 (dependent vs. nondependent smokers) $\times 3$ (valence, arousal and dominance ratings) multiple analysis of variance. The main effect of the group was significant, $F(1,89)=4.31$, p $<0.05$, as well as 
Table 1. Valence, arousal and dominance statistics for dependent and nondependent smokers

\begin{tabular}{|c|c|c|c|c|c|c|c|}
\hline \multirow[t]{2}{*}{ Ratings } & \multicolumn{3}{|c|}{ Dependent smokers $(n=46)$} & \multicolumn{3}{|c|}{ Nondependent smokers $(n=45)$} & \multirow[t]{2}{*}{ Posthoc comparisons } \\
\hline & mean $\pm S D$ & $\min$. & $\max$. & mean $\pm S D$ & $\min$. & $\max$ & \\
\hline Valence & $5.28 \pm 1.25$ & 3.15 & 8.25 & $5.38 \pm 1.07$ & 3.52 & 8.30 & \multirow{3}{*}{$\begin{array}{l}\text { n.s. } \\
\text { nondependent smokers }>\text { dependent smokers } \\
\text { nondependent smokers }>\text { dependent smokers }\end{array}$} \\
\hline Arousal & $5.73 \pm 1.43$ & 3.05 & 8.42 & $6.53 \pm 1.56$ & 4.13 & 9.00 & \\
\hline Dominance & $5.82 \pm 1.30$ & 2.75 & 8.18 & $6.41 \pm 1.33$ & 4.50 & 9.00 & \\
\hline
\end{tabular}

max. = Maximum mean for the group; $\min .=$ minimum mean for the group; .s. $=$ nonsignificant.

the main effect of the subjective ratings, $F(2,178)=25.79$, $\mathrm{p}<0.001$. In addition, the interaction between group and subjective ratings was also significant, $F(2,178)=4.75$, $\mathrm{p}<0.050$. Posthoc comparisons revealed that dependent smokers are significantly more aroused, $t(89)=2.56, \mathrm{p}<$ 0.050 , and dominated, $t(89)=2.12, \mathrm{p}<0.050$, by the tobacco-related pictures than are nondependent smokers. However, no significant difference was found in valence ratings, $t(89)=0.39, \mathrm{p}=0.70$.

\section{Discussion}

The aim of the present study was to develop a database of 60 tobacco-related pictures based on the validation procedure of the IAPS. Compared with other databases such as the NAPS, the GSP provides a larger number of pictures specifically related to tobacco. Moreover, the GSP comprises various subtypes of tobacco-related pictures (smoking products and tobacco-related cues), which allows researchers to choose the most appropriate pictures for their research. One of the main advantages of the study is that it provides normative data for the pictures incorporated in the GSP. Thus, investigators can select the stimuli they need on the basis of arousal, dominance and/or valence characteristics (provided for both nondependent and dependent smokers). Furthermore, it is possible to select stimuli on more than one rating (e.g. a study requiring positive and arousing stimuli) and to use stimuli from both the GSP and the IAPS (for smoking-unrelated pictures), as well as from the Geneva Appetitive Alcohol Pictures database [16] for alcohol-related pictures, because the three databases have been validated with the same procedure. Moreover, taking into account that Munoz et al. [15] have assessed 35 smoking pictures with the IAPS rating method, researchers can now choose from a large number of stimuli. The study by Munoz et al. [15] aimed, however, to assess links between image visualization and craving rather than to validate a set of smoking-related pictures. The present study specifically aimed to validate the GSP database by adding to previous works a larger number of smokingrelated pictures, comparative norms for nondependent smokers and dependent smokers, and details of normative values for each picture. Finally, subjective ratings of the pictures were significantly correlated with smoking patterns as measured by the FTND. This finding supports the usefulness of the database in further studies about nicotine smoking and dependence. Dominance and arousal are strongly related dimensions, meaning that pictures that trigger elevated emotional arousal are also associated with low perceived control. Furthermore, these two ratings were found to significantly differentiate dependent smokers from nondependent smokers on the basis of their FTND scores. This was not the case for valence ratings. This latter finding is in accordance with previous results showing the importance of arousal in addictive and tobacco dependence phenomena, as well as in the severity of the dependence [8, $17,22]$. Previous research showed more equivocal results regarding the role of dominance in emotion-related research and addiction. It was suggested [15] that this dimension (also called strength confidence or control) is more susceptible to variation across research contexts, cravings and possibly motivational stages regarding the change of a given behavior (e.g. contemplation, determination).

One intriguing finding was that the time since the last cigarette was smoked did not significantly correlate with any of the subjective ratings. Thus, it seems that subjective ratings were more influenced by nicotine dependence than by transient changes such as those linked to a cigarette recently smoked. This result is in line with the hypothesis of Tiffany et al. [23] postulating that cue reac- 
tivity is probably a highly stable phenomenon that is poorly influenced by nicotine intake status.

One limitation to the study is its cross-sectional nature, which implies the absence of a test-retest measure of the subjective ratings. Another potential limitation is related to the fact that the sample is composed solely of participants living in Switzerland, whereas tobacco products vary across countries. Nevertheless, the number and the variety of pictures composing the GSP database allow scientists and clinicians to choose which pictures are more suitable for them. Further studies on other European and non-European samples may increase the validity of the GSP. Although the study sample size is relatively low (91 smokers in total), it is quite similar to that of other validation studies of IAPS pictures [19]. The size is, however, lower than that of the NAPS study (more than 300 subjects), which included only six tobacco-related pictures [12]. The sample is also mainly composed of young adults and so the findings should be confirmed in samples of older smokers. Furthermore, the present study relies only on subjective evaluation and does not comprise psychophysiological measures of arousal (e.g. skin conductance). Finally, this preliminary validation of the GSP was conducted without a nonsmoking control group, which could be problematic for studies requiring the norms for nonsmokers. Further validation of the GSP will require assessment by a nonsmoking control group in order to publish picture ratings of nonsmokers. Despite these limitations, the GSP can be considered as a normative database of affective pictures, providing a large number of stimuli for investigators who conduct research on tobacco.

\section{Disclosure Statement}

The authors have no conflicts of interest to declare.

Appendix. Mean ratings and standard deviations for the 60 pictures of the GSP

\begin{tabular}{|c|c|c|c|c|c|c|c|}
\hline \multirow{2}{*}{$\begin{array}{l}\text { Picture } \\
\text { No. }\end{array}$} & \multirow{2}{*}{$\begin{array}{l}\text { Type of } \\
\text { picture }\end{array}$} & \multicolumn{3}{|c|}{ Dependent smokers $(n=46)$} & \multicolumn{3}{|c|}{ Nondependent smokers $(n=45)$} \\
\hline & & valence & arousal & dominance & valence & arousal & dominance \\
\hline 1 & Smoking & $3.50 \pm 1.76$ & $5.67 \pm 2.02$ & $5.78 \pm 2.35$ & $4.64 \pm 2.06$ & $6.44 \pm 1.91$ & $6.30 \pm 1.90$ \\
\hline 2 & Smoking & $4.67 \pm 2.12$ & $5.48 \pm 1.75$ & $5.50 \pm 1.99$ & $4.76 \pm 1.72$ & $6.47 \pm 1.71$ & $6.42 \pm 1.75$ \\
\hline 3 & Product & $4.98 \pm 2.58$ & $5.87 \pm 2.32$ & $5.65 \pm 2.23$ & $4.95 \pm 2.35$ & $6.23 \pm 2.12$ & $6.23 \pm 1.85$ \\
\hline 4 & Smoking & $4.72 \pm 2.12$ & $5.04 \pm 2.26$ & $5.87 \pm 2.24$ & $4.95 \pm 1.72$ & $6.02 \pm 2.05$ & $6.65 \pm 1.70$ \\
\hline 5 & Smoking & $4.89 \pm 1.75$ & $5.93 \pm 2.07$ & $5.87 \pm 2.01$ & $4.89 \pm 1.71$ & $6.82 \pm 1.74$ & $6.49 \pm 1.73$ \\
\hline 6 & Related cue & $5.15 \pm 2.80$ & $6.39 \pm 2.45$ & $5.83 \pm 2.36$ & $4.98 \pm 1.88$ & $7.18 \pm 1.91$ & $6.96 \pm 1.98$ \\
\hline 7 & Product & $5.09 \pm 2.37$ & $6.09 \pm 2.01$ & $5.47 \pm 2.20$ & $5.13 \pm 1.75$ & $6.69 \pm 1.72$ & $6.42 \pm 1.71$ \\
\hline 8 & Smoking & $6.07 \pm 2.04$ & $5.59 \pm 2.07$ & $6.15 \pm 2.12$ & $5.91 \pm 2.28$ & $5.58 \pm 2.25$ & $6.42 \pm 1.89$ \\
\hline 9 & Product & $7.83 \pm 1.82$ & $5.76 \pm 2.53$ & $6.20 \pm 2.79$ & $8.04 \pm 1.28$ & $6.24 \pm 2.31$ & $6.42 \pm 2.30$ \\
\hline 10 & Smoking & $6.62 \pm 2.45$ & $5.87 \pm 2.16$ & $6.22 \pm 2.31$ & $7.23 \pm 1.66$ & $6.02 \pm 2.18$ & $6.49 \pm 2.02$ \\
\hline 11 & Product & $7.59 \pm 1.98$ & $6.09 \pm 2.70$ & $6.96 \pm 2.75$ & $7.82 \pm 1.54$ & $6.40 \pm 1.95$ & $6.43 \pm 2.25$ \\
\hline 12 & Smoking & $4.83 \pm 2.31$ & $5.26 \pm 2.22$ & $5.70 \pm 2.23$ & $4.31 \pm 1.76$ & $6.40 \pm 2.20$ & $6.18 \pm 1.76$ \\
\hline 13 & Product & $6.33 \pm 1.93$ & $5.74 \pm 2.07$ & $6.26 \pm 2.36$ & $6.93 \pm 1.78$ & $6.79 \pm 1.93$ & $6.70 \pm 1.99$ \\
\hline 14 & Product & $4.00 \pm 2.04$ & $4.87 \pm 2.11$ & $4.24 \pm 2.24$ & $3.89 \pm 1.73$ & $6.13 \pm 2.49$ & $6.18 \pm 2.08$ \\
\hline 15 & Smoking & $6.24 \pm 2.02$ & $6.17 \pm 2.24$ & $6.35 \pm 1.75$ & $5.88 \pm 1.98$ & $6.56 \pm 2.22$ & $6.42 \pm 2.28$ \\
\hline 16 & Product & $5.07 \pm 2.55$ & $5.60 \pm 2.43$ & $6.02 \pm 2.58$ & $4.91 \pm 2.01$ & $7.09 \pm 1.68$ & $6.82 \pm 1.61$ \\
\hline 17 & Smoking & $6.09 \pm 2.20$ & $5.76 \pm 2.22$ & $7.00 \pm 2.13$ & $6.91 \pm 1.66$ & $6.67 \pm 1.81$ & $6.26 \pm 1.93$ \\
\hline 18 & Product & $4.22 \pm 2.05$ & $5.00 \pm 2.02$ & $4.65 \pm 1.82$ & $4.49 \pm 1.82$ & $6.71 \pm 1.98$ & $6.31 \pm 1.98$ \\
\hline 19 & Smoking & $5.46 \pm 2.03$ & $5.80 \pm 1.89$ & $5.83 \pm 1.82$ & $5.53 \pm 2.16$ & $6.19 \pm 2.46$ & $6.77 \pm 1.80$ \\
\hline 20 & Smoking & $4.30 \pm 2.22$ & $4.74 \pm 1.99$ & $5.83 \pm 2.36$ & $4.82 \pm 2.10$ & $6.42 \pm 2.25$ & $6.16 \pm 2.06$ \\
\hline 21 & Smoking & $3.80 \pm 2.02$ & $5.15 \pm 2.44$ & $4.78 \pm 2.62$ & $4.69 \pm 1.76$ & $6.51 \pm 2.12$ & $6.33 \pm 2.09$ \\
\hline 22 & Product & $6.13 \pm 2.20$ & $6.24 \pm 2.16$ & $6.61 \pm 2.37$ & $7.16 \pm 1.40$ & $6.93 \pm 1.70$ & $6.76 \pm 1.87$ \\
\hline 23 & Product & $5.87 \pm 2.35$ & $6.51 \pm 2.39$ & $5.89 \pm 2.32$ & $5.87 \pm 2.03$ & $6.82 \pm 2.00$ & $6.84 \pm 1.78$ \\
\hline 24 & Product & $7.26 \pm 1.68$ & $6.67 \pm 2.30$ & $6.76 \pm 2.26$ & $6.47 \pm 1.84$ & $6.82 \pm 2.11$ & $6.91 \pm 1.77$ \\
\hline 25 & Product & $4.22 \pm 2.12$ & $6.33 \pm 2.53$ & $5.39 \pm 2.42$ & $4.44 \pm 1.87$ & $6.38 \pm 2.12$ & $6.20 \pm 2.04$ \\
\hline 26 & Smoking & $5.33 \pm 2.36$ & $5.72 \pm 2.26$ & $5.35 \pm 2.27$ & $5.64 \pm 2.17$ & $6.62 \pm 2.12$ & $6.76 \pm 1.80$ \\
\hline 27 & Product & $4.07 \pm 2.38$ & $4.76 \pm 2.64$ & $4.61 \pm 2.77$ & $4.13 \pm 2.14$ & $5.89 \pm 2.48$ & $5.67 \pm 2.50$ \\
\hline 28 & Smoking & $4.41 \pm 2.27$ & $4.96 \pm 2.00$ & $5.17 \pm 2.41$ & $5.00 \pm 1.89$ & $6.51 \pm 2.22$ & $6.13 \pm 2.33$ \\
\hline 29 & Related cue & $3.96 \pm 2.36$ & $6.41 \pm 2.41$ & $6.63 \pm 2.51$ & $4.71 \pm 2.18$ & $7.27 \pm 2.07$ & $6.47 \pm 2.11$ \\
\hline 30 & Product & $4.30 \pm 2.59$ & $5.26 \pm 2.49$ & $4.74 \pm 2.05$ & $3.96 \pm 1.92$ & $6.24 \pm 2.26$ & $6.07 \pm 1.97$ \\
\hline 31 & Smoking & $5.26 \pm 2.20$ & $6.02 \pm 2.09$ & $5.72 \pm 1.93$ & $5.02 \pm 2.04$ & $6.76 \pm 1.91$ & $6.53 \pm 1.69$ \\
\hline
\end{tabular}


Appendix (continued)

\begin{tabular}{|c|c|c|c|c|c|c|c|}
\hline \multirow{2}{*}{$\begin{array}{l}\text { Picture } \\
\text { No. }\end{array}$} & \multirow{2}{*}{$\begin{array}{l}\text { Type of } \\
\text { picture }\end{array}$} & \multicolumn{3}{|c|}{ Dependent smokers $(n=46)$} & \multicolumn{3}{|c|}{ Nondependent smokers $(n=45)$} \\
\hline & & valence & arousal & dominance & valence & arousal & dominance \\
\hline 32 & Product & $5.13 \pm 2.42$ & $5.51 \pm 2.07$ & $5.84 \pm 1.97$ & $5.20 \pm 1.90$ & $6.58 \pm 2.14$ & $6.27 \pm 2.10$ \\
\hline 33 & Product & $2.35 \pm 1.66$ & $4.07 \pm 2.70$ & $4.46 \pm 3.08$ & $3.36 \pm 2.23$ & $5.69 \pm 2.63$ & $6.47 \pm 2.19$ \\
\hline 34 & Product & $4.89 \pm 2.40$ & $5.39 \pm 2.69$ & $4.96 \pm 2.45$ & $4.60 \pm 2.17$ & $5.87 \pm 2.22$ & $5.44 \pm 2.23$ \\
\hline 35 & Product & $5.65 \pm 2.51$ & $6.30 \pm 2.34$ & $6.24 \pm 2.26$ & $5.22 \pm 1.93$ & $6.64 \pm 2.04$ & $6.00 \pm 2.50$ \\
\hline 36 & Related cue & $5.04 \pm 2.09$ & $4.85 \pm 2.43$ & $6.28 \pm 2.41$ & $5.36 \pm 1.90$ & $6.69 \pm 2.09$ & $5.62 \pm 2.04$ \\
\hline 37 & Smoking & $4.76 \pm 1.80$ & $5.80 \pm 2.20$ & $5.80 \pm 2.29$ & $5.00 \pm 1.92$ & $6.62 \pm 2.27$ & $6.24 \pm 2.12$ \\
\hline 38 & Product & $5.89 \pm 2.15$ & $6.80 \pm 1.94$ & $6.35 \pm 2.09$ & $5.82 \pm 2.07$ & $6.62 \pm 2.11$ & $6.33 \pm 1.98$ \\
\hline 39 & Smoking & $4.70 \pm 2.58$ & $5.07 \pm 2.29$ & $4.24 \pm 1.86$ & $4.60 \pm 1.81$ & $6.49 \pm 2.11$ & $6.04 \pm 2.11$ \\
\hline 40 & Related cue & $5.09 \pm 2.32$ & $5.28 \pm 2.60$ & $6.09 \pm 2.70$ & $4.73 \pm 2.19$ & $6.62 \pm 2.33$ & $6.31 \pm 2.11$ \\
\hline 41 & Smoking & $4.63 \pm 2.11$ & $5.22 \pm 2.40$ & $5.57 \pm 2.45$ & $5.40 \pm 2.05$ & $6.31 \pm 2.45$ & $6.67 \pm 1.98$ \\
\hline 42 & Smoking & $4.87 \pm 1.82$ & $5.91 \pm 2.10$ & $5.33 \pm 1.97$ & $5.40 \pm 1.86$ & $6.80 \pm 2.20$ & $6.69 \pm 1.81$ \\
\hline 43 & Smoking & $6.63 \pm 2.25$ & $6.11 \pm 2.24$ & $6.70 \pm 1.94$ & $6.36 \pm 2.22$ & $6.39 \pm 2.55$ & $6.34 \pm 2.23$ \\
\hline 44 & Smoking & $4.85 \pm 2.02$ & $5.39 \pm 2.32$ & $5.78 \pm 2.18$ & $5.40 \pm 2.03$ & $6.44 \pm 2.25$ & $6.51 \pm 1.84$ \\
\hline 45 & Smoking & $4.44 \pm 2.34$ & $5.69 \pm 2.51$ & $5.53 \pm 2.59$ & $5.53 \pm 1.78$ & $6.80 \pm 2.04$ & $6.49 \pm 1.94$ \\
\hline 46 & Smoking & $3.84 \pm 2.33$ & $4.24 \pm 2.66$ & $3.84 \pm 2.34$ & $4.09 \pm 2.04$ & $5.78 \pm 2.68$ & $5.44 \pm 2.35$ \\
\hline 47 & Product & $7.17 \pm 1.82$ & $7.04 \pm 2.10$ & $7.15 \pm 2.17$ & $6.96 \pm 1.66$ & $6.84 \pm 2.25$ & $6.96 \pm 1.99$ \\
\hline 48 & Smoking & $4.83 \pm 2.27$ & $5.07 \pm 2.58$ & $5.41 \pm 2.39$ & $4.53 \pm 1.98$ & $6.33 \pm 2.24$ & $6.31 \pm 1.94$ \\
\hline 49 & Product & $5.89 \pm 2.51$ & $5.89 \pm 2.06$ & $6.76 \pm 2.15$ & $6.13 \pm 2.12$ & $6.91 \pm 2.22$ & $6.76 \pm 2.02$ \\
\hline 50 & Smoking & $5.15 \pm 2.33$ & $5.70 \pm 2.26$ & $5.63 \pm 2.16$ & $5.00 \pm 1.98$ & $6.27 \pm 2.28$ & $6.33 \pm 1.64$ \\
\hline 51 & Product & $7.96 \pm 1.56$ & $6.30 \pm 2.53$ & $7.15 \pm 2.56$ & $8.02 \pm 1.50$ & $6.20 \pm 2.43$ & $6.62 \pm 2.39$ \\
\hline 52 & Related cue & $5.80 \pm 2.17$ & $6.24 \pm 2.30$ & $7.07 \pm 2.23$ & $5.04 \pm 1.76$ & $7.27 \pm 2.19$ & $6.69 \pm 2.13$ \\
\hline 53 & Smoking & $5.07 \pm 2.10$ & $6.20 \pm 2.39$ & $6.30 \pm 2.22$ & $5.98 \pm 1.97$ & $6.84 \pm 2.22$ & $7.02 \pm 1.75$ \\
\hline 54 & Smoking & $5.37 \pm 2.52$ & $5.43 \pm 2.46$ & $4.52 \pm 2.50$ & $5.11 \pm 2.38$ & $6.20 \pm 2.65$ & $6.57 \pm 2.20$ \\
\hline 55 & Related cue & $4.87 \pm 2.57$ & $6.20 \pm 2.48$ & $5.72 \pm 2.44$ & $4.31 \pm 2.16$ & $7.20 \pm 2.33$ & $6.53 \pm 2.26$ \\
\hline 56 & Product & $7.83 \pm 1.64$ & $6.41 \pm 2.56$ & $7.30 \pm 2.38$ & $7.16 \pm 1.97$ & $6.62 \pm 2.23$ & $6.31 \pm 2.33$ \\
\hline 57 & Smoking & $5.11 \pm 2.86$ & $6.37 \pm 2.66$ & $7.15 \pm 2.11$ & $4.82 \pm 2.58$ & $6.31 \pm 2.70$ & $6.69 \pm 2.38$ \\
\hline 58 & Smoking & $5.98 \pm 2.56$ & $7.13 \pm 2.19$ & $6.50 \pm 2.21$ & $6.40 \pm 2.05$ & $6.89 \pm 2.18$ & $7.02 \pm 1.91$ \\
\hline 59 & Product & $6.02 \pm 2.45$ & $6.35 \pm 2.30$ & $5.87 \pm 2.31$ & $4.53 \pm 2.37$ & $6.51 \pm 2.60$ & $6.29 \pm 2.42$ \\
\hline 60 & Smoking & $5.04 \pm 2.42$ & $5.15 \pm 2.29$ & $5.15 \pm 2.44$ & $5.16 \pm 2.19$ & $6.42 \pm 2.32$ & $6.28 \pm 2.21$ \\
\hline
\end{tabular}

\section{References}

1 Carter BL, Tiffany ST: Cue-reactivity and the future of addiction research. Addiction 1999;94:349-351.

-2 Tiffany ST, Carter BL: Is craving the source of compulsive drug use? J Psychopharmacol 1998; 12:23-30.

3 Carter BL, Robinson JD, Lam CY, et al: A psychometric evaluation of cigarette stimuli used in a cue reactivity study. Nicotine Tob Res 2006;8:361-369.

4 Parker AB, Gilbert DG: Brain activity during anticipation of smoking-related and emotionally positive pictures in smokers and nonsmokers: a new measure of cue reactivity. Nicotine Tob Res 2008;10:16271631.

5 Vollstädt-Klein S, Loeber S, Winter S, et al: Attention shift towards smoking cues relates to severity of dependence, smoking behavior and breath carbon monoxide. Eur Addict Res 2011;17:217-224.
-6 Field M, Cox WM: Attentional bias in addictive behaviors: a review of its development, causes, and consequences. Drug Alcohol Depend 2008;97:1-20.

7 Carter BL, Lam CY, Robinson JD, et al: Generalized craving, self-report of arousal, and cue reactivity after brief abstinence. Nicotine Tob Res 2009;11:823-826.

8 Carter BL, Tiffany ST: Meta-analysis of cuereactivity in addiction research. Addiction 1999;94:327-340.

\ Janes AC, Pizzagalli DA, Richardt S, et al: Brain reactivity to smoking cues prior to smoking cessation predicts ability to maintain tobacco abstinence. Biol Psychiatry 2010;67:722-729.

10 McClernon FJ, Gilbert DG: Human functional neuroimaging in nicotine and tobacco research: basics, background, and beyond. Nicotine Tob Res 2004;6:941-959.

11 Drobes DJ, Carter AC, Goldman MS: Alcohol expectancies and reactivity to alcoholrelated and affective cues. Exp Clin Psychopharmacol 2009;17:1-9.
12 Stritzke WG, Breiner MJ, Curtin JJ, Lang AR: Assessment of substance cue reactivity: advances in reliability, specificity, and validity. Psychol Addict Behav 2004;18:148-159.

13 George MS, Anton RF, Bloomer C, et al: Activation of prefrontal cortex and anterior thalamus in alcoholic subjects on exposure to alcohol-specific cues. Arch Gen Psychiatry 2001;58:345-352.

14 Park MS, Sohn JH, Suk JA, Kim SH, Sohn S, Sparacio R: Brain substrates of craving to alcohol cues in subjects with alcohol use disorder. Alcohol Alcohol 2007;42:417-422.

15 Munoz MA, Viedma-del-Jesus MI, Fernandez-Santaella MC, Peralta-Ramırez MI, Cepeda-Benito A, Vila J: Assessment of tobacco craving by means of the affective image visualization paradigm. Motiv Emot 2010;34:93-103.

16 Billieux J, Khazaal Y, Oliveira S, et al: The Geneva Appetitive Alcohol Pictures (GAAP): development and preliminary validation. Eur Addict Res 2011;17:225-230. 
-17 Kaplan RF, Cooney NL, Baker LH, Gillespie RA, Meyer RE, Pomerleau OF: Reactivity to alcohol-related cues: physiological and subjective responses in alcoholics and nonproblem drinkers. J Stud Alcohol 1985;46:267272.

18 Heatherton TF, Kozlowski LT, Frecker RC, Fagerstrom KO: The Fagerstrom Test for Nicotine Dependence: a revision of the Fagerstrom Tolerance Questionnaire. Br J Addict 1991;86:1119-1127.
19 Lang P, Bradley M, Cuthbert B: The International Affective Pictures System (IAPS) Technical Manual and Affective Ratings. Gainesville, University of Florida, 1999.

20 Etter JF, Duc TV, Perneger TV: Validity of the Fagerström test for nicotine dependence and of the Heaviness of Smoking Index among relatively light smokers. Addiction 1999;94:269-281.

21 Pomerleau CS, Carton SM, Lutzke ML, Flessland KA, Pomerleau OF: Reliability of the Fagerstrom Tolerance Questionnaire and the Fagerstrom Test for Nicotine Dependence. Addict Behav 1994;19:33-39.
22 Monti PM, Binkoff JA, Abrams DB, Zwick WR, Nirenberg TD, Liepman MR: Reactivity of alcoholics and nonalcoholics to drinking cues. J Abnorm Psychol 1987;96:122-126.

23 Tiffany ST, Cox LS, Elash CA: Effects of transdermal nicotine patches on abstinenceinduced and cue-elicited craving in cigarette smokers. J Consult Clin Psychol 2000;68: 233-240. 